\title{
Journal of \\ Materials Chemistry A
}

Materials for energy and sustainability

rsc.li/materials-a

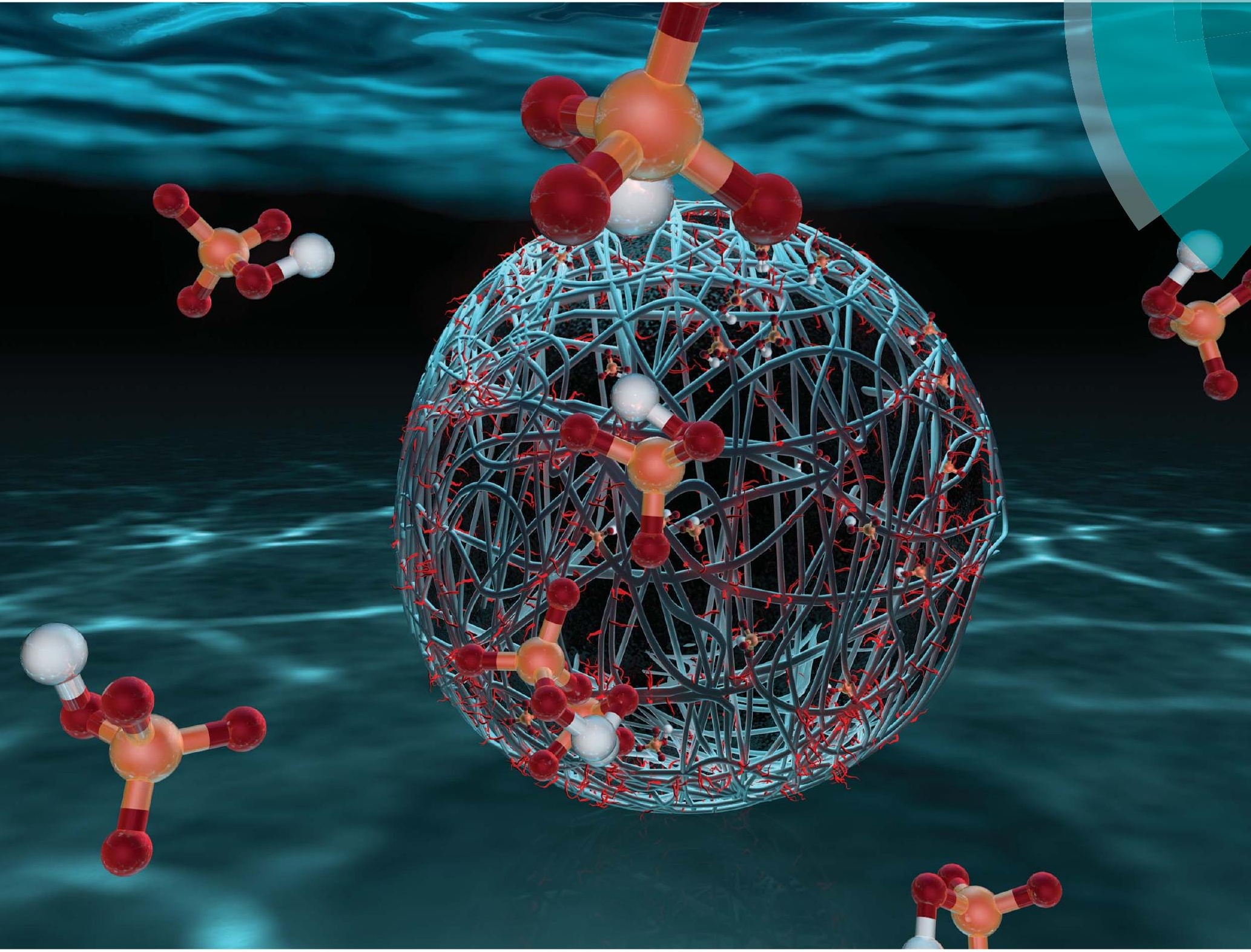

ISSN 2050-7488

ROYAL SOCIETY OF CHEMISTRY
PAPER

Louis C. P. M. de Smet et al.

$\mathrm{Fe}_{3} \mathrm{O}_{4}$ nanoparticles coated with a guanidinium-functionalized polyelectrolyte extend the $\mathrm{pH}$ range for phosphate binding 
Check for updates

Cite this: J. Mater. Chem. A, 2017, 5, 18476

\section{$\mathrm{Fe}_{3} \mathrm{O}_{4}$ nanoparticles coated with a guanidinium- functionalized polyelectrolyte extend the $\mathrm{pH}$ range for phosphate binding $\dagger$}

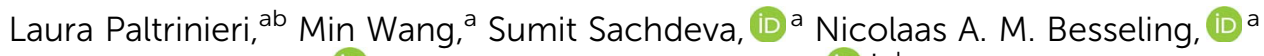 \\ Ernst J. R. Sudhölter iD a and Louis C. P. M. de Smet (iD *abc
}

\begin{abstract}
In this work commercially available $\mathrm{Fe}_{3} \mathrm{O}_{4} \mathrm{NPs}$ were coated with polyallylamine hydrochloride (PAH) and $\mathrm{PAH}$ functionalized with guanidinium groups ( $\mathrm{PAH}-\mathrm{Gu}$ ) for investigating the phosphate adsorption properties under alkaline conditions. The coating can be prepared easily and rapidly and results in $\mathrm{Fe}_{3} \mathrm{O}_{4}$ NPs with improved properties related to phosphate binding and colloidal stability. At a low initial phosphate concentration $\left(2 \mathrm{mg} \mathrm{L}^{-1}\right)$, the novel $\mathrm{Fe}_{3} \mathrm{O}_{4} \mathrm{QPAH}-\mathrm{Gu}$ material was able to remove phosphate rather independently of the $\mathrm{pH}$ condition $\left(4.0,3.6\right.$ and $3.7 \mathrm{mg} \mathrm{g}^{-1}$ at $\mathrm{pH}=5,8$ and 10 , respectively), whereas for the uncoated $\mathrm{Fe}_{3} \mathrm{O}_{4}$ NPs the amount of adsorbed phosphate drops by $>75 \%$ upon changing from acidic to alkaline conditions $\left(0.84 \mathrm{mg} \mathrm{g}^{-1}\right.$ at $\left.\mathrm{pH}=10\right)$. Under alkaline conditions, the fastest adsorption was observed for $\mathrm{Fe}_{3} \mathrm{O}_{4} \mathrm{QPAH}-\mathrm{Gu}$ followed by $\mathrm{Fe}_{3} \mathrm{O}_{4} \mathrm{aPAH}$ and $\mathrm{Fe}_{3} \mathrm{O}_{4}$. This can be related to the additional interaction forces due to the presence of primary amine groups (in PAH and PAH-Gu) and Gu groups (in PAH-Gu only) in coatings. Over $80 \%$ of the phosphate adsorbed on the novel $\mathrm{Fe}_{3} \mathrm{O}_{4} \mathrm{QPAH}-\mathrm{Gu}$ material was successfully desorbed and the coated NPs were re-used over three adsorption/desorption cycles. This work will stimulate the design and preparation of functionalized polyelectrolytes for an extended area of applications, especially for the selective removal of target compounds from wastewater.
\end{abstract}

Received 10th May 2017

Accepted 4th July 2017

DOI: $10.1039 / \mathrm{c} 7 \mathrm{ta0} 4054 \mathrm{~g}$

rsc.li/materials-a

\section{Introduction}

The uncontrolled discharge of phosphate-containing products as present in aqueous streams from agricultural and cosmetic sectors $^{\mathbf{1 , 2}}$ has increased eutrophication processes, i.e. the rapid growth of aquatic algae in lakes and rivers., ${ }^{3,4}$ These processes contribute to an unbalanced aquatic ecology and to a decrease of water quality. Phosphate is therefore considered to be one of the most critical contaminants present in wastewater. Many countries have set a standard for the discharge of phosphate into water. ${ }^{5}$ For instance, the European Union recently regulated a maximum value of $0.07 \mu \mathrm{g} \mathrm{P}$ per $\mathrm{L}$ for rivers and $100 \mu \mathrm{g} \mathrm{P}$ per $\mathrm{L}$ for lakes to reduce the risk of eutrophication. ${ }^{6}$ In order to meet such strict requirements and to manage the high

${ }^{a}$ Delft University of Technology, Department of Chemical Engineering, Van der Maasweg 9, 2629 HZ Delft, The Netherlands

${ }^{b}$ Wetsus - European Centre of Excellence for Sustainable Water Technology, Oostergoweg 9, 8932 PG Leeuwarden, The Netherlands

${ }^{c}$ Wageningen University \& Research, Laboratory of Organic Chemistry, Stippeneng 4, 6708 WE Wageningen, The Netherlands. E-mail: louis.desmet@wur.nl

$\dagger$ Electronic supplementary information (ESI) available: ${ }^{1} \mathrm{H}-\mathrm{NMR}$ of the synthesized PAH-Gu (Fig. S1), pictures showing the stability of several suspensions (Fig. S2 and S3). Pseudo second-order linear curves (Fig. S4) and pseudo second-order non-linear curve fitting parameters (Table S1). See DOI: 10.1039/c7ta04054g phosphorus demand at the same time, ${ }^{7,8}$ the recovery of phosphorus from phosphate-contaminated aqueous media has been recognized as a challenging key strategy. For this purpose different technologies have been developed, including biological treatments, ${ }^{9}$ membrane-based processes, ${ }^{\mathbf{1 0 , 1 1}}$ crystallization, ${ }^{12,13}$ flotation, ${ }^{14}$ and adsorption-based processes. ${ }^{15}$ From this list of well-known techniques, adsorption processes have high potential. This is mainly related to their low operational costs, high efficiency, low energy consumption and their versatility to be applicable in different wastewater sources. ${ }^{15}$

Among candidates for phosphate adsorbents, iron oxides are considered to be highly promising. ${ }^{16}$ This is because of (1) their high selectivity to bind phosphate in the presence of competing anions and (2) their easy introduction in municipal wastewater treatment plants (WWTPs). Furthermore, a good adsorbent is identified by, amongst others, the available specific adsorption area. For this reason, a lot of attention is now paid to develop new nano-sized adsorbents, because of their high-surface-areato-volume ratio. ${ }^{17}$ Nanoparticles of iron oxide $\left(\mathrm{Fe}_{3} \mathrm{O}_{4} \mathrm{NPs}\right)$ fulfill these conditions and even possess magnetic properties, making easy separations possible by using external magnetic fields. ${ }^{18}$ Phosphate adsorption onto $\mathrm{Fe}_{3} \mathrm{O}_{4}$ NPs occurs through an innersphere complex, due to the presence of surface hydroxyl groups. ${ }^{16,19}$ When the $\mathrm{pH}$ is lower than the point of zero charge (PZC), the surface of the iron oxide nanoparticles is positively 
charged, which promotes binding and surface adsorption of phosphate anions. The lower the $\mathrm{pH}$, the more charge on the surface and therefore a higher binding capacity. ${ }^{20,21}$ However, at lower $\mathrm{pH}$ values the amount of phosphate anions decreases, as they are converted to phosphoric acid. ${ }^{22}$ This becomes significantly below $\mathrm{pH}<\mathrm{p} K_{\mathrm{a} 1}=2.1$. The $\mathrm{pH}$ of water streams in WWTPs is typically $6-8,{ }^{23,24}$ i.e., around the PZC of the $\mathrm{Fe}_{3} \mathrm{O}_{4}$ NPs. At such $\mathrm{pH}$ values, the surface charge is slightly positive, neutral or slightly negative, which has a large negative impact on the phosphate anion binding capacity. In the mentioned $\mathrm{pH}$ range, the phosphates are monoanionic and partly dianionic $\left(\mathrm{p} K_{\mathrm{a} 2}=7.2\right) .{ }^{22}$ Moreover, in this $\mathrm{pH}$ range the NPs aggregate to precipitate, due to the decreased inter-particle electrostatic repulsions. Thus, for phosphate separation processes at $\mathrm{pH}$ values around the PZC of $\mathrm{Fe}_{3} \mathrm{O}_{4} \mathrm{NPs}$, there is room for improvement. For this reason, different types of chemical surface modifications have been applied by the attachment of specific ligands, including amino groups, ${ }^{25}$ metal organic frameworks (MOFs) ${ }^{19}$ polymers,${ }^{26,27}$ layered double hydroxides $(\mathrm{LDHs})^{28}$ and graphene. ${ }^{29}$ These examples illustrate well the effectiveness of surface functionalization in terms of controlling the affinity for a specific target species. Yet, it would be interesting to further employ these surface modification strategies in order to extend the use of iron oxide nanoparticles for phosphate anion binding at higher $\mathrm{pH}$ values, where unmodified iron oxide is otherwise less effective.

Receptor-functionalized polyelectrolytes (PEs) can bind to surfaces of opposite charge $\mathrm{e}^{\mathbf{3 0}-32}$ and can contribute to nanoparticle stabilization, ${ }^{33}$ while the receptor groups introduce selectivity for binding certain targets. Recent advances in this direction resulted in the availability of polyelectrolytes that were functionalized with, e.g., biotin, fluorescent probes and guanidinium groups to address chelation and the selective capture of His-tagged proteins, ${ }^{34,35}$ biosensing, ${ }^{36}$ fingermark visualization, ${ }^{37}$ and ion selectivity. ${ }^{38}$ Interestingly, polyelectrolyte functionalization and the subsequent modification of NPs do not require complicated chemical steps and can be performed rapidly in aqueous media.

In the current study, we present the concept of a simple surface modification of commercially available $\mathrm{Fe}_{3} \mathrm{O}_{4}$ NPs using polyelectrolytes functionalized with phosphate-receptors. For the receptor we have chosen the guanidinium moiety, which is able to coordinate phosphate ions in a wide range of $\mathrm{pH}$ values. ${ }^{39,40}$ The Gu-functionalized polyelectrolyte was applied to modify the $\mathrm{Fe}_{3} \mathrm{O}_{4}$ NPs. The thus-obtained NPs are characterized in terms of their morphology, thermal stability and surface properties. The effect of the $\mathrm{pH}$ on the phosphate adsorption is investigated in detail, as well as the kinetics of the process. The obtained results were compared with those of bare $\mathrm{Fe}_{3} \mathrm{O}_{4}$ NPs as well as $\mathrm{Fe}_{3} \mathrm{O}_{4}$ NPs coated with a non-functionalized polyelectrolyte.

\section{Experimental}

\section{Materials}

Poly(allylamine hydrochloride) (PAH, $\left.M_{\mathrm{w}} \sim 15000 \mathrm{Da}\right)$ guanidine acetic acid (GAA, 99\%), 1-ethyl-3-(3-dimethylaminopropyl) carbodiimide (EDC, commercial grade) and $N$-hydroxysuccinimide (NHS, 98\%) were purchased from Sigma-Aldrich and used without any further purification. $1 \mathrm{M} \mathrm{HCl}$ and $1 \mathrm{M}$ $\mathrm{NaOH}$ (analytical reagent grade, obtained from Fluka, Germany) were used for $\mathrm{pH}$ adjustments. Sodium dihydrogen phosphate $\left(\mathrm{NaH}_{2} \mathrm{PO}_{4} \cdot \mathrm{H}_{2} \mathrm{O}\right.$, Acros Organics) was used in phosphate removal experiments. Commercial iron oxide nanoparticles $\left(\mathrm{Fe}_{3} \mathrm{O}_{4} \mathrm{NPs}, 8 \mathrm{~nm}\right.$ in diameter as determined by TEM) were purchased as a $3 \mathrm{wt} \%$ acidic aqueous dispersion from PlasmaChem GmbH (Germany) without any organic stabilizer. All aqueous solutions were prepared using Milli-Q water (Milli-Q Ultrapure Water System, Millipore $22 \mu \mathrm{m}$ ).

\section{Preparation of $\mathrm{PAH}-\mathrm{Gu}, \mathrm{Fe}_{3} \mathrm{O}_{4} @ \mathrm{PAH}$ and $\mathrm{Fe}_{3} \mathrm{O}_{4} @ \mathrm{PAH}-\mathrm{Gu}$}

PAH-Gu (Scheme 1, top right) was obtained by the reaction of GAA with a part of the amino groups of PAH following the procedure published earlier by our group. ${ }^{38}{ }^{1} \mathrm{H}$-NMR was used to confirm the chemical structure (ESI, Fig. S1†) and to calculate the degree of amino group functionalization by guanidinium (Gu) moieties; it was found to be $\sim 30 \%$ for the batch used in the current work. In order to study the effect of present $\mathrm{Gu}$ groups, non-functionalized $\mathrm{PAH}$ was used as a reference.

Next, the $\mathrm{Fe}_{3} \mathrm{O}_{4}$ NPs were modified with PAH or PAH-Gu via the following procedure. ${ }^{41}$ Aqueous solutions of $\mathrm{PAH}$ and $\mathrm{PAH}-$ $\mathrm{Gu}\left(2.5 \mathrm{~g} \mathrm{~L}^{-1}\right)$ were prepared by sonication using a probe sonicator (Cole-Parmer CPX750, 30\% power, 750 watts) for $20 \mathrm{~min}$ and simultaneous cooling by placing the tube in ice. Similarly, a $\mathrm{Fe}_{3} \mathrm{O}_{4} \mathrm{NP}$ suspension $\left(0.5 \mathrm{~g} \mathrm{~L}^{-1}\right)$ was prepared in MilliQ water and sonicated under the same conditions. After sonication, the $\mathrm{pH}$ of all solutions was adjusted to 9.5 by the addition of drops of concentrated $\mathrm{HCl}$ or $\mathrm{NaOH}(1 \mathrm{M})$. At this $\mathrm{pH}$ value the $\mathrm{Fe}_{3} \mathrm{O}_{4}$ NPs have a negative surface charge, while the polyelectrolytes are positively charged. The $\mathrm{Fe}_{3} \mathrm{O}_{4} \mathrm{NP}$ suspension was added drop-wise to the polyelectrolyte solutions and stirred for $24 \mathrm{~h}$ at room temperature (RT) to ensure complete adsorption at the
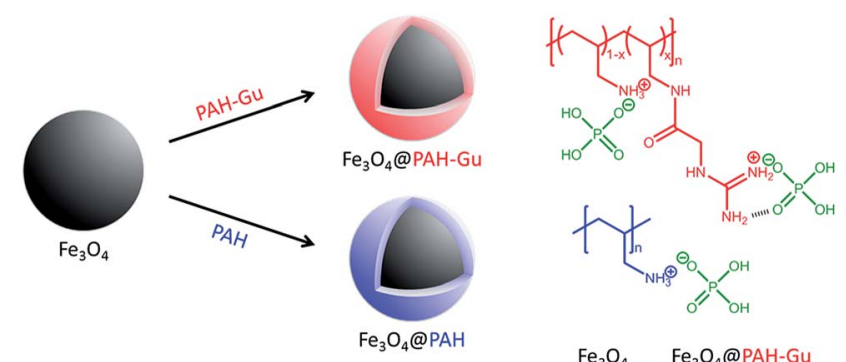

1. Sonication of aqueous PE \& NP solutions

2. Adjustment $\mathrm{pH}$ to 9.5

3. Addition of NP suspension to PE solution

4. Centrifugation $(3 x)$

5. Redispersion in water

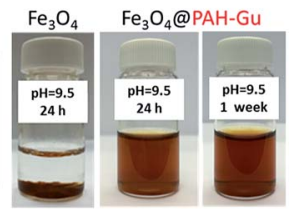

Scheme 1 A schematic showing the three different NPs (top left) and the interactions between amino-phosphate and guanidinium-phosphate, shown for the monovalent anion (top right). Brief stepwise description of the coating process of $\mathrm{Fe}_{3} \mathrm{O}_{4} \mathrm{NPs}$ with (functionalized) polyelectrolytes (in the grey-colored box, bottom left), and pictures of different NP suspensions at $\mathrm{pH}=9.5$ (bottom right). 
$\mathrm{Fe}_{3} \mathrm{O}_{4}$ NP surface. The functionalized NPs were separated from the excess of PEs by three cycles of centrifugation, decantation and washing (Heraeus instrument D-37520 Osterode, Germany) at $17000 \mathrm{rpm}\left(20 \mathrm{~min}\right.$ at $\left.20^{\circ} \mathrm{C}\right)$. The product was finally redispersed in $40 \mathrm{~mL}$ of MilliQ water to maintain the initial concentration and then sonicated to obtain uniform solutions of $\mathrm{Fe}_{3} \mathrm{O}_{4} @ \mathrm{PAH}$ and $\mathrm{Fe}_{3} \mathrm{O}_{4} @ \mathrm{PAH}-\mathrm{Gu}$. A schematic overview of the coating procedure and the different types of $\mathrm{Fe}_{3} \mathrm{O}_{4}$ NPs is presented in Scheme 1.

\section{Characterization}

The ${ }^{1} \mathrm{H}$ NMR spectrum of the PAH-Gu polymer was obtained using a Bruker AVANCE 400 NMR spectrometer with $\mathrm{D}_{2} \mathrm{O}$ as solvent.

Modified NPs were studied with Fourier Transform InfraRed spectroscopy (Nicolet 8700 FT-IR Spectrometer) by mixing the NPs with $\mathrm{KBr}$ and pressing pellets. The spectral range of FT-IR was from $4000 \mathrm{~cm}^{-1}$ to $500 \mathrm{~cm}^{-1}$ with a resolution of $4 \mathrm{~cm}^{-1}$.

X-ray Photoelectron Spectroscopy (XPS, Thermo Fisher Scientific, K-Alpha model) was used to determine the atomic composition of the modified NP surfaces. In more detail, a monochromatic $\mathrm{Al} \mathrm{K} \alpha \mathrm{X}$-ray source was used with a spot size of $400 \mu \mathrm{m}$ at a pressure of $10^{-7} \mathrm{mbar}$. A constant pass energy of $200 \mathrm{eV}$ for the survey spectra and $50 \mathrm{eV}$ for the detailed highresolution spectra was used. The flood gun was turned on during the measurement to compensate for potential charging of the surface. The peak position was adjusted based on the internal standard C1s peak at $284.8 \mathrm{eV}$, with an accuracy of $\pm 0.05 \mathrm{eV}$. Avantage processing software was used to analyze all spectra.

ThermoGravimetric Analysis (TGA) measurements were performed with Thermal Analysis (TA) Instruments equipment from RT to $550{ }^{\circ} \mathrm{C}$ at a heating rate of $10{ }^{\circ} \mathrm{C} \min ^{-1}$ under continuous air purging.

The size and morphology of the unmodified and modified NPs were studied using a Transmission Electron Microscope (TEM, JEOL JEM-1400 Plus, USA) operated at $120 \mathrm{kV}$. A holey carbon support film (200 meshes, Quantifoil $囚$ ) was dipped into the NP-containing solution and then dried at room temperature overnight. TEM images were analyzed by using Image J software and the mean size value of each NP system was calculated based on 20 separately determined diameters.

The hydrodynamic diameter $\left(D_{\mathrm{h}}\right)$ of NPs was determined at $25^{\circ} \mathrm{C}$ by Dynamic Light Scattering (DLS) using a Zetasizer Nano ZS900 (Malvern, UK). The instrument was operated at a backscattering angle of $173^{\circ}$ with a laser beam with a wavelength of $633 \mathrm{~nm}$. The same instrument was used to measure the $\zeta$-potential at $25{ }^{\circ} \mathrm{C}$ for all samples and measurements were performed in triplicate. To this end, an aqueous suspension of $\mathrm{Fe}_{3} \mathrm{O}_{4} \mathrm{NPs}\left(0.5 \mathrm{mg} \mathrm{mL}^{-1}\right)$ was prepared by adding $167 \mu \mathrm{L}$ of the original concentrated NP solution into $10 \mathrm{~mL}$ MilliQ water. Samples for $\zeta$-potential measurements were prepared by diluting $80 \mu \mathrm{L}$ of the above-prepared NP suspension $\left(0.5 \mathrm{mg} \mathrm{mL} \mathrm{mL}^{-1}\right)$ to $10 \mathrm{~mL}$ using MilliQ water. The solution was sonicated using a probe sonicator $(30 \%, 750$ watts, cooling in an ice bath, $6 \mathrm{~min}$ ) to break the existing aggregates. In the last step, the $\mathrm{pH}$ was adjusted to the desired values by using $1 \mathrm{M} \mathrm{NaOH}$ and $1 \mathrm{M} \mathrm{HCl}$. The same procedure was used to determine the $\zeta$ potential of all NP systems, as well of the pure PEs (PAH and $\mathrm{PAH}-\mathrm{Gu}$ ), where a solution of $0.5 \mathrm{mg} \mathrm{mL}^{-1}$ in MilliQ water was used. All the measurements were done $5 \mathrm{~min}$ after the sonication procedure to minimize possible differences due to colloidal instability.

\section{Batch adsorption experiments}

Phosphate adsorption experiments were performed for $\mathrm{Fe}_{3} \mathrm{O}_{4}$, $\mathrm{Fe}_{3} \mathrm{O}_{4} @ \mathrm{PAH}$, and $\mathrm{Fe}_{3} \mathrm{O}_{4} @ \mathrm{PAH}-\mathrm{Gu}$ NPs. All desired phosphate solutions, including the standard known concentration of phosphate for calibration measurements, were prepared by diluting a stock solution (1000 mg L $\mathrm{L}^{-1}$ of $\mathrm{NaH}_{2} \mathrm{PO}_{4}$ in $250 \mathrm{~mL}$ ). The phosphate adsorption was studied as a function of time starting with an initial phosphate concentration of $2 \mathrm{mg} \mathrm{L}^{-1}$, taken from the stock solution, and an adsorbent solution of $0.5 \mathrm{~g} \mathrm{~L}^{-1}$ in $30 \mathrm{~mL}$. The adsorbed amount was deduced from the reduction of the phosphate concentration according to the work optimized by Yoon et al. ${ }^{42}$ In contrast to other studies, ${ }^{42,43}$ we have decided to keep a fixed initial adsorbent concentration and to focus on the effect of $\mathrm{pH}$ on the adsorption process. In this study the $\mathrm{pH}$ conditions have a great impact not only on the stability of the suspension of NPs and their surface charges, but also on the type of speciation of phosphate involved in the adsorption process. Before starting the experiments, the $\mathrm{pH}$ of both the adsorbent solution and phosphate solution was adjusted to the desired value. Phosphate was added to NP solutions, followed by stirring at RT for $24 \mathrm{~h}$. Samples were taken at different times and centrifuged (Eppendorf AG, Germany) at $13000 \mathrm{rpm}$ for $1 \mathrm{~h}$. The phosphate adsorption efficiency was measured through UV-vis spectroscopy (UVIKON XL, Beun De Ronde) by using the ascorbic acid method. ${ }^{44,45}$

\section{Adsorption and desorption cycles}

$\mathrm{Fe}_{3} \mathrm{O}_{4} @ P A H G u$ NPs were subjected to three adsorption and desorption cycles to test the reversibility of the binding process as well as the reusability of the coated NPs. In more detail, a solution containing $5 \mathrm{mg} \mathrm{L}{ }^{-1}$ of $\mathrm{NaH}_{2} \mathrm{PO}_{4}$ was added to $3 \mathrm{~mL}$ of a $0.5 \mathrm{~g} \mathrm{~L}^{-1} \mathrm{Fe}_{3} \mathrm{O}_{4}$ @PAHGu suspension at $\mathrm{pH}=5$. The adsorption experiment was performed by stirring at RT for $24 \mathrm{~h}$ followed by a centrifugation step ( $1 \mathrm{~h}$ at $13000 \mathrm{rpm}$ ). The desorption experiment was done by adding a $10 \mathrm{mM}$ $\mathrm{NaCl}$ solution to the $\mathrm{Fe}_{3} \mathrm{O}_{4}$ @PAHGu NPs that were obtained after the centrifugation step of the first adsorption. The solutions were stirred for $3 \mathrm{~h}$ at RT and the resulting solution was separated from the NPs by centrifugation $(1 \mathrm{~h}$ at $13000 \mathrm{rpm})$. Before the $2^{\text {nd }}$ and $3^{\text {rd }}$ adsorption cycle, $\mathrm{Fe}_{3} \mathrm{O}_{4} @ P A H G u$ NPs were washed twice with MilliQ water while stirring for $30 \mathrm{~min}$ each time after which the water was removed by centrifugation ( $1 \mathrm{~h}$ at $13000 \mathrm{rpm}$, each time). All phosphate-containing solutions were analysed through Ion Chromatography (930 Compact IC Flex, $150 \mathrm{~mm}$ A Supp 5 column, Metrohm). 


\section{Results and discussion}

Given the importance of electrostatic interactions in the surface modification using polyelectrolytes, ${ }^{33,46}$ we first present and discuss the $\zeta$-potential data of the $\mathrm{PAH}$ and $\mathrm{PAH}-\mathrm{Gu}$ separately, and $\mathrm{Fe}_{3} \mathrm{O}_{4}$ NPs as such. Next, FTIR, XPS, TGA and TEM data are given to characterize the bare and modified $\mathrm{Fe}_{3} \mathrm{O}_{4}$ NPs. The phosphate sorption studies of the NPs are split into three different topics: (i) pH effects, (ii) kinetic study and (iii) reversibility of phosphate binding.

\section{$\zeta$-Potential investigation of PEs and $\mathrm{Fe}_{3} \mathrm{O}_{4} \mathrm{NPS}$}

Fig. 1 shows the $\zeta$-potential of bare $\mathrm{Fe}_{3} \mathrm{O}_{4}$ NPs as well as of PAH and $\mathrm{PAH}-\mathrm{Gu}$ in aqueous solutions as a function of the solution $\mathrm{pH}$. It is observed that for all cases the zeta potential becomes less positive with increasing $\mathrm{pH}$ value.

For the unmodified $\mathrm{Fe}_{3} \mathrm{O}_{4}$ NPs the zeta potential changes from a positive $\left(\mathrm{Fe}-\mathrm{OH}_{2}{ }^{+}\right.$groups are in excess) to a negative ( $\mathrm{Fe}-$ $\mathrm{O}^{-}$groups are in excess) sign around $\mathrm{pH}=7$, reflecting the $\mathrm{PZC}$ as has been reported in the literature. ${ }^{47}$

In contrast, $\mathrm{PAH}$ and $\mathrm{PAH}-\mathrm{Gu}$ polyelectrolyte solutions remain positive over the whole investigated $\mathrm{pH}$ region. $\mathrm{PAH}-\mathrm{Gu}$ shows a higher positive surface charge compared to the (unfunctionalized) $\mathrm{PAH}$. This can be easily understood in terms of the respective $\mathrm{p} K_{\mathrm{a}}$ values of $\mathrm{PAH}$ and $\mathrm{Gu}$, which are 8-9 for the primary amine of $\mathrm{PAH}^{\mathbf{4 8 , 4 9}}$ and 13 for the guanidinium group present in $\mathrm{PAH}-\mathrm{Gu}^{50}{ }^{50}$ Furthermore, for $\mathrm{PAH}-\mathrm{Gu}$ the $\zeta$-potential data at $\mathrm{pH}<6.5$ show a plateau behavior, which is absent for $\mathrm{PAH}$ and the $\mathrm{Fe}_{3} \mathrm{O}_{4}$ NPs in the studied $\mathrm{pH}$ window. This indicates that the overall surface-charge density of $\mathrm{PAH}-\mathrm{Gu}$ at $\mathrm{pH}<$ 6 is constant. This difference may be associated with the differences in the PZC of the respective materials, including a shift of the apparent dissociation constant of $\mathrm{PAH}\left(\mathrm{p} K_{\mathrm{a}(\mathrm{app})}\right)$ due to local changes of the electrostatic environment ${ }^{51}$ and, for

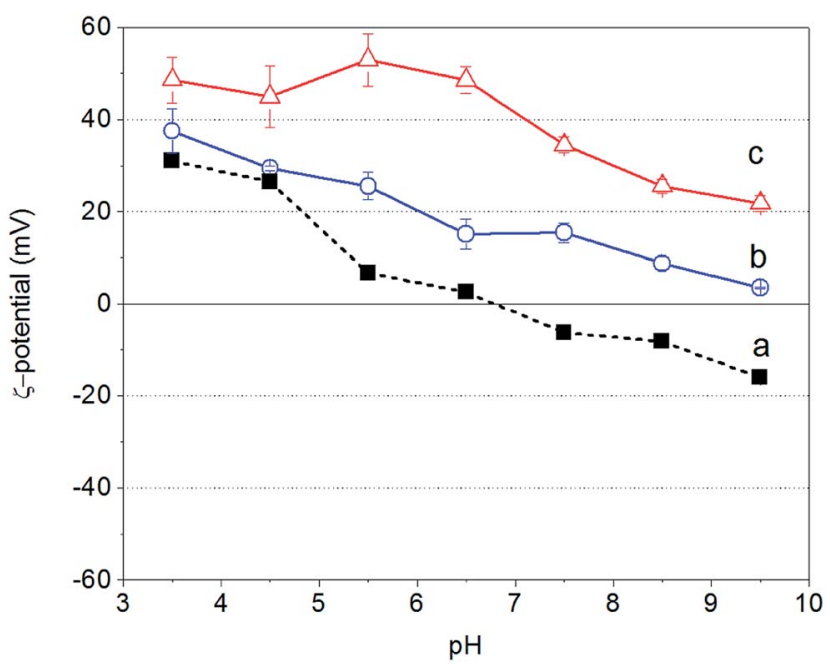

Fig. 1 -Potential as a function of solution $\mathrm{pH}$ for (a) an aqueous suspension of unmodified $\mathrm{Fe}_{3} \mathrm{O}_{4} \mathrm{NPs}\left(0.5 \mathrm{~g} \mathrm{~L}^{-1}\right.$, black squares), (b) an aqueous solution of $0.5 \mathrm{~g}$ PAH per $\mathrm{L}$ (blue circles), and (c) an aqueous solution of $0.5 \mathrm{~g} \mathrm{PAH}-\mathrm{Gu}$ per $\mathrm{L}$ (red triangles).
$\mathrm{PAH}-\mathrm{Gu}$ a saturation of chargeable groups under acidic $\mathrm{pH}$ conditions.

To conclude this part, the results show that within the $\mathrm{pH}$ window of $\sim 7$ to $\sim 9.5$ the unmodified $\mathrm{Fe}_{3} \mathrm{O}_{4}$ NPs are negatively charged, while both PEs are positively charged. In addition, from the literature it is known that $\mathrm{Fe}_{3} \mathrm{O}_{4}$ NPs are maximally covered by weak polyelectrolytes (like $\mathrm{PAH}$ ) if the $\mathrm{pH}$ is similar to the polyelectrolyte $\mathrm{p} K_{\mathrm{a}}$ value. ${ }^{52}$ We have therefore chosen to perform our experiments at a $\mathrm{pH}$ of 9.5, the $\mathrm{p} K_{\mathrm{a}}$ value of $\mathrm{PAH}$, for both $\mathrm{PAH}$ and $\mathrm{PAH}-\mathrm{Gu}$ modifications.

\section{Characterization of coated $\mathrm{Fe}_{3} \mathrm{O}_{4} \mathrm{NPs}$}

The FTIR spectra of bare $\mathrm{Fe}_{3} \mathrm{O}_{4}$ NPs, $\mathrm{Fe}_{3} \mathrm{O}_{4} @ \mathrm{PAH}$, and $\mathrm{Fe}_{3^{-}}$ $\mathrm{O}_{4}$ @PAH-Gu as well as those of the pure PEs are shown in Fig. 2. The data show that the modified NPs are covered with $\mathrm{PAH}$ or PAH-Gu. In all cases a large contribution between 3404 $\mathrm{cm}^{-1}$ and $3017 \mathrm{~cm}^{-1}$ is observed, which can be associated with the $\mathrm{O}-\mathrm{H}$ bond stretching. Its broadness originates from $\mathrm{H}$ bridge formation with physically adsorbed water, which was used as a solvent and can be entrapped between the polymeric chains (see also TEM and TGA analysis; vide intra)..$^{53}$ The presence of iron oxide is confirmed by the observed stretching of $\mathrm{Fe}-$ $\mathrm{O}$ at $577 \mathrm{~cm}^{-1}$ in the cases of $\mathrm{Fe}_{3} \mathrm{O}_{4}$ NPs (black, dashed), $\mathrm{Fe}_{3}$ $\mathrm{O}_{4} @ \mathrm{PAH}$ (blue, dashed) and $\mathrm{Fe}_{3} \mathrm{O}_{4} @ \mathrm{PAH}-\mathrm{Gu}$ (red, dashed). ${ }^{54}$ The success of the PAH coating process becomes clear from the typical peaks at $2918 \mathrm{~cm}^{-1}$ and $2850 \mathrm{~cm}^{-1}$ that are associated with $\mathrm{C}-\mathrm{C}$ stretching and two peaks at $1575 \mathrm{~cm}^{-1}$ and $1541 \mathrm{~cm}^{-1}$ of the $\mathrm{C}-\mathrm{N}$ and $\mathrm{N}-\mathrm{H}$ bending, which compare well with bands present in the FTIR spectrum of PAH (blue). Finally, the bands at $1604 \mathrm{~cm}^{-1}$ and $1506 \mathrm{~cm}^{-1}$ can be assigned to the bending vibration related to the amino group. ${ }^{55}$ Likewise, in agreement with the bare PAH-Gu spectrum (red), the coating of NPs with $\mathrm{PAH}-\mathrm{Gu}$ is confirmed by the presence of two peaks at $2918 \mathrm{~cm}^{-1}$

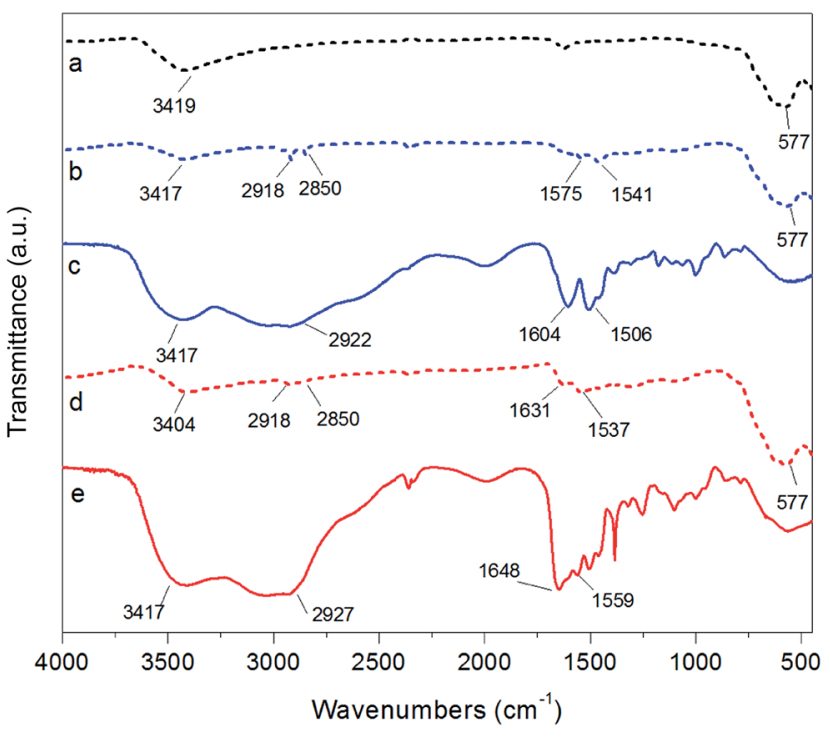

Fig. 2 FTIR spectra of (a) bare $\mathrm{Fe}_{3} \mathrm{O}_{4} \mathrm{NPs}$ (black, dashed), (b) $\mathrm{Fe}_{3}-$ $\mathrm{O}_{4}\left(\mathrm{aPAH}\right.$ (blue, dashed), (c) PAH polymer (blue, solid), (d) $\mathrm{Fe}_{3} \mathrm{O}_{4}(\mathrm{aPAH}-$ Gu (red, dashed), and (e) PAH-Gu polymer (red, solid). 
and $2850 \mathrm{~cm}^{-1}$ for $\mathrm{C}-\mathrm{C}$ stretching, a peak at $1631 \mathrm{~cm}^{-1}$ assigned to the stretching of $\mathrm{C}=\mathrm{N}$ bond from the $\mathrm{Gu}$ group and a peak at $1537 \mathrm{~cm}^{-1}$ of the $\mathrm{N}-\mathrm{H}$ bending. ${ }^{38,56}$ It should be mentioned that in both spectra of $\mathrm{Fe}_{3} \mathrm{O}_{4} @ \mathrm{PAH}$ and $\mathrm{Fe}_{3} \mathrm{O}_{4} @ \mathrm{PAH}-\mathrm{Gu}$, the positions of the characteristic peaks of primary amine and amide bonds shift to some extent with respect to the corresponding bare PEs. This can be explained by the interaction between iron ions and charged groups of PEs and the formation of amino complexes. ${ }^{57}$

XPS was used to further map the surface chemistry of NPs before and after modification (Table 1). The successful NP functionalization is evident from the $\mathrm{N} / \mathrm{Fe}$ ratio that increases upon the preparation of the coating from 0 (bare $\mathrm{Fe}_{3} \mathrm{O}_{4} \mathrm{NPs}$ ) to 0.30 and 0.60 for $\mathrm{Fe}_{3} \mathrm{O}_{4} @ \mathrm{PAH}$ and $\mathrm{Fe}_{3} \mathrm{O}_{4} @ \mathrm{PAH}-\mathrm{Gu}$, respectively. Moreover, with respect to the bare NPs, the $\mathrm{C} / \mathrm{Fe}$ ratio is higher in the presence of the PEs and this can be associated with the alkyl polymer backbone and methylene groups in the side chains. Oxygen is measured in all samples, which can be related to $\mathrm{OH}$ groups present at the $\mathrm{Fe}_{3} \mathrm{O}_{4}$ NP surface and the $\mathrm{C}=\mathrm{O}$ in the $\mathrm{Fe}_{3} \mathrm{O}_{4}$ @PAH-Gu system.

Carbon is detected in $\mathrm{Fe}_{3} \mathrm{O}_{4}$ as well, and this can be related to hydrocarbon surface contamination often observed on surfaces. ${ }^{58}$ While the $\mathrm{C} / \mathrm{Fe}$ ratio of $\mathrm{Fe}_{3} \mathrm{O}_{4} @ \mathrm{PAH}$ is higher than that of $\mathrm{Fe}_{3} \mathrm{O}_{4} @ \mathrm{PAH}-\mathrm{Gu}$, the contribution of carbon contamination makes it hard to draw any conclusion on the degree of coverage based on $\mathrm{C} / \mathrm{Fe}$. An indication of the amount of PEs bound to the NP surface can be deduced from the N/Fe ratio. Taking into account a degree of $\mathrm{Gu}$ group substitution of $30 \%$ (see the chemical structure reported in Scheme 1), the calculated amount of $\mathrm{N}$ per repeating unit in $\mathrm{PAH}-\mathrm{Gu}$ is 1.9 times higher than that for PAH (considering $0.3 \times 4(\mathrm{~N})+0.7 \times 1(\mathrm{~N})$ ). From XPS analysis a ratio of $(0.60 / 0.30)=2$ was observed, indicating that a similar amount of both polyelectrolytes is bound to the NPs.

Additional evidence of the changed surface chemistry of the NPs was obtained from TGA analysis (Fig. 3). Bare $\mathrm{Fe}_{3} \mathrm{O}_{4}$ (line a) showed hardly any weight loss for the indicated temperature range (residual of 98\%). This small weight reduction can be attributed to the loss of water physically adsorbed at the NP surface combined with the loss of condensed groups at temperatures higher than $100{ }^{\circ} \mathrm{C} .{ }^{59}$ In contrast, two degradation steps clearly appear for $\mathrm{Fe}_{3} \mathrm{O}_{4} @ \mathrm{PAH}$ (line b) and $\mathrm{Fe}_{3} \mathrm{O}_{4} @ \mathrm{PAH}-$ $\mathrm{Gu}$ (line c). The first step at $30-120^{\circ} \mathrm{C}$ refers to the loss of water. The presence of water is due to both physically adsorbed water at modified NP surfaces and the hydration shell of ions (ammonium and chlorine) of the polyelectrolyte chains, which is found to be almost the same for both systems (in accordance with the FTIR spectra). The second weight loss at $250-400{ }^{\circ} \mathrm{C}$

Table 1 XPS elemental ratios of bare and polyelectrolyte-modified NPS

\begin{tabular}{lccc}
\hline & $\mathrm{C} / \mathrm{Fe}$ & $\mathrm{O} / \mathrm{Fe}$ & $\mathrm{N} / \mathrm{Fe}$ \\
\hline $\mathrm{Fe}_{3} \mathrm{O}_{4}$ & 1.67 & 1.64 & - \\
$\mathrm{Fe}_{3} \mathrm{O}_{4} @ \mathrm{PAH}$ & 6.02 & 4.69 & 0.30 \\
$\mathrm{Fe}_{3} \mathrm{O}_{4} @ \mathrm{PAH}-\mathrm{Gu}$ & 2.44 & 2.52 & 0.60
\end{tabular}

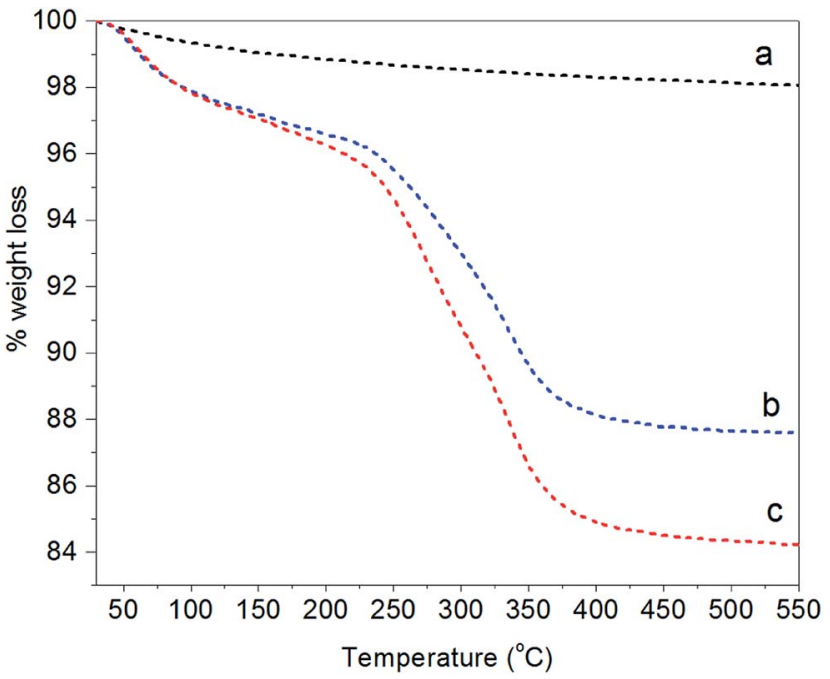

Fig. 3 TGA curves showing the fractional weight loss of (a) bare $\mathrm{Fe}_{3} \mathrm{O}_{4}$ (black), (b) $\mathrm{Fe}_{3} \mathrm{O}_{4}\left(\mathrm{aPAH}\right.$ (blue), and (c) $\mathrm{Fe}_{3} \mathrm{O}_{4} @ \mathrm{aPAHGu}$ (red).

can be related to the breakdown of the PEs. The residuals of $\mathrm{Fe}_{3} \mathrm{O}_{4} @ \mathrm{PAH}$ and $\mathrm{Fe}_{3} \mathrm{O}_{4} @ \mathrm{PAH}-\mathrm{Gu}$ overall drop to $87 \%$ and $84 \%$, respectively. The weight drop can be attributed to the bonded polyelectrolyte at the NP surface. The difference between the drop for $\mathrm{Fe}_{3} \mathrm{O}_{4} @ \mathrm{PAH}$ and $\mathrm{Fe}_{3} \mathrm{O}_{4} @ \mathrm{PAH}-\mathrm{Gu}$ is due to the $\mathrm{Gu}$ modification, considering that the average mass per monomer unit is larger for $\mathrm{PAH}-\mathrm{Gu}$ than that for $\mathrm{PAH}$.

The morphology of NPs was examined with TEM; the images of $\mathrm{Fe}_{3} \mathrm{O}_{4}$ NPs, $\mathrm{Fe}_{3} \mathrm{O}_{4} @ \mathrm{PAH}$, and $\mathrm{Fe}_{3} \mathrm{O}_{4} @ \mathrm{PAH}-\mathrm{Gu}$ are shown in Fig. 4. In the absence of a polymeric coating, $\mathrm{Fe}_{3} \mathrm{O}_{4}$ NPs show a typical spherical shape. ${ }^{60}$ The same spherical shape can also be observed in images (b) and (c); in addition, a smooth and transparent layer is seen around the NPs, likely due to the presence of the polymeric coating (c). ${ }^{61}$ Table 2 lists the mean diameters of the NPs as obtained from TEM analysis. $\mathrm{Fe}_{3} \mathrm{O}_{4}$ NPs were found to have a diameter of $8 \pm 2 \mathrm{~nm}$, confirming the specifications given by the supplier. The diameters of $\mathrm{Fe}_{3} \mathrm{O}_{4} @ \mathrm{PAH}$ and $\mathrm{Fe}_{3} \mathrm{O}_{4} @ \mathrm{PAH}-\mathrm{Gu}$, including the additional smooth layer, are $11 \pm 2 \mathrm{~nm}$, indicating an adsorbed polyelectrolyte layer thickness of $c a .3 \mathrm{~nm}$ (TEM-based size distribution plots are presented in ESI Fig. S2 $\dagger){ }^{62}$

Table 2 summarizes the size data of our investigated NPs as obtained from TEM and DLS (hydrodynamic diameters) and zeta potential measurements. At $\mathrm{pH}=9.5$, the unmodified and polyelectrolyte-modified NPs have hydrodynamic diameters much larger than the sizes of single particles observed by TEM. This is due to the agglomeration of these NPs in solution. This agglomeration is reduced for the NPs modified with a polyelectrolyte: $86 \mathrm{~nm}$ observed for the unmodified $\mathrm{Fe}_{3} \mathrm{O}_{4} \mathrm{NPs}$, compared to $65 \mathrm{~nm}$ and $41 \mathrm{~nm}$ for the $\mathrm{Fe}_{3} \mathrm{O}_{4} @ \mathrm{PAH}$ and $\mathrm{Fe}_{3} \mathrm{O}_{4} @ \mathrm{PAH}-\mathrm{Gu}$, respectively. The difference is related to the colloidal stability, which is increased for polyelectrolyte-modified NPs, thus preventing aggregation. ${ }^{29,30,58,63,64}$ We also observed a stable suspension for both PE-modified NPs, while the unmodified $\mathrm{Fe}_{3} \mathrm{O}_{4}$ NPs precipitated after $24 \mathrm{~h}$ at $\mathrm{pH}=9.5$ (Scheme 1, bottom left and ESI Fig. S3 and $\mathrm{S} 4 \dagger$ ). 


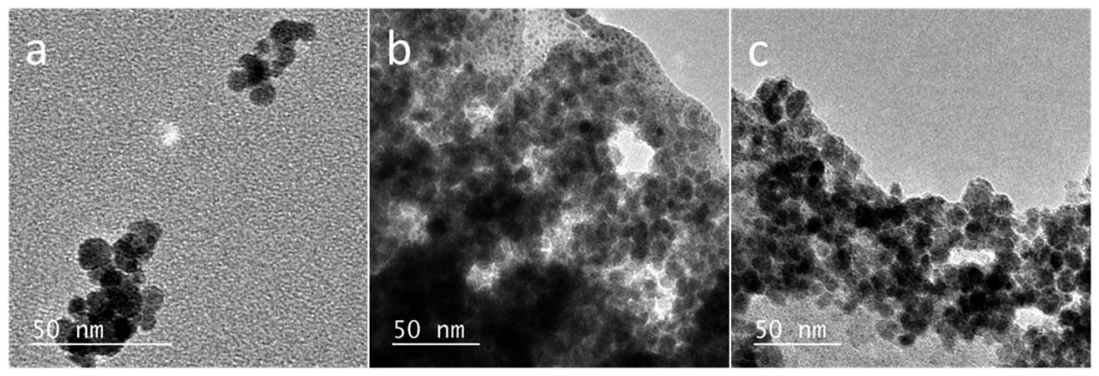

Fig. 4 TEM images of (a) bare $\mathrm{Fe}_{3} \mathrm{O}_{4}$, (b) $\mathrm{Fe}_{3} \mathrm{O}_{4}$ (aPAH NPs, and (c) $\mathrm{Fe}_{3} \mathrm{O}_{4}$ (aPAH-Gu NPs.

The stability of the NP suspension at $\mathrm{pH}=9.5$ as observed from DLS was confirmed with $\zeta$-potential, which changes sign upon modification to $+26 \mathrm{mV}$ and $+32 \mathrm{mV}$ for the $\mathrm{PAH}$ and $\mathrm{PAH}-$ $\mathrm{Gu}$ coatings, respectively. The positive $\zeta$-potential values strongly confirm the presence of polycations at the NP surface. ${ }^{61}$ Moreover, it should be noted that the magnitude of the surface potential reflects the level of electrostatic repulsion between NPs. A higher zeta potential gives more repulsion and therefore a more stable suspension. From these zeta potential measurements it is now clearly understood why the $\mathrm{Fe}_{3} \mathrm{O}_{4}$ NPs start to agglomerate, while the PE-modified NPs are still stable. From the results obtained, it is evident that the addition of a $\mathrm{Gu}$ moiety altered the $\mathrm{Fe}_{3} \mathrm{O}_{4}$ properties; this is in terms of not only reversing the surface charge to a positive value (as is the case for Gu-free PAH), but also increasing the absolute charge density, leading to an increased colloidal stability. Again, this can be explained by the differences in the PZC between the amino-PAH and Gu moiety ${ }^{65}$ Images of the NP suspension at different $\mathrm{pH}$ values after $24 \mathrm{~h}$ and $\mathrm{Fe}_{3} \mathrm{O}_{4} @ \mathrm{PAH}-\mathrm{Gu}$ after 1 week are shown in Fig. S2 and S3 in the ESI. $\dagger$

\section{Phosphate adsorption: effect of $\mathbf{p H}$}

In order to map the $\mathrm{pH}$-dependency of phosphate adsorption at our (modified) NPs, three $\mathrm{pH}$ values were chosen for the adsorption experiments: $\mathrm{pH}=5, \mathrm{pH}=8$ and $\mathrm{pH}=10$. Within the $\mathrm{pH}$ window from 5 to 10 the degree of dissociation of phosphoric acid decreases accordingly, thus at $\mathrm{pH}=5 \mathrm{H}_{2} \mathrm{PO}_{4}{ }^{-}$ is predominant, at $\mathrm{pH}=8 \mathrm{H}_{2} \mathrm{PO}_{4}{ }^{-}$and $\mathrm{HPO}_{4}{ }^{2-}$ are equally present, while at $\mathrm{pH}=10$ mostly $\mathrm{HPO}_{4}{ }^{2-}$ can be expected. ${ }^{22}$ The adsorption experiments were performed at a fixed concentration of $0.5 \mathrm{~g}$ (modified) NP per $\mathrm{L}$ and $2 \mathrm{mg} \mathrm{NaH} \mathrm{N}_{2} \mathrm{PO}_{4}$ per $\mathrm{L}$; thus there is always an excess of adsorbent. Fig. 5 shows the results of the phosphate adsorption as a function of $\mathrm{pH}$ for $\mathrm{Fe}_{3} \mathrm{O}_{4} \mathrm{NPs}$,

Table 2 Sizes and zeta potentials of our investigated NPs

\begin{tabular}{lccr}
\hline Type of NPs & $\begin{array}{l}\text { TEM diameter } \\
(\mathrm{nm})\end{array}$ & $D_{\mathrm{h}}{ }^{a, b}(\mathrm{~nm})$ & \multicolumn{1}{c}{\begin{tabular}{l}
\multicolumn{1}{c}{$(\mathrm{motential})^{b}$} \\
$(\mathrm{mV})$
\end{tabular}} \\
\hline $\mathrm{Fe}_{3} \mathrm{O}_{4}$ & $8 \pm 2$ & 86 (PDI 0.7) & $-16.7 \pm 0.7$ \\
$\mathrm{Fe}_{3} \mathrm{O}_{4} @ \mathrm{PAH}$ & $11 \pm 2$ & 65 (PDI 0.5) & $26.0 \pm 1.2$ \\
$\mathrm{Fe}_{3} \mathrm{O}_{4} @ \mathrm{PAH}-\mathrm{Gu}$ & $11 \pm 2$ & 41 (PDI 0.3) & $32.0 \pm 1.7$
\end{tabular}

${ }^{a}$ From DLS. ${ }^{b} \mathrm{pH}=9.5$.
$\mathrm{Fe}_{3} \mathrm{O}_{4} @ \mathrm{PAH}$ and $\mathrm{Fe}_{3} \mathrm{O}_{4} @ \mathrm{PAH}-\mathrm{Gu}$ after equilibration for $24 \mathrm{~h}$ at RT as determined by the ascorbic acid/UV method. ${ }^{45}$

At $\mathrm{pH}=5$ all NPs show a similar amount of phosphate adsorbed. Under these conditions, the phosphate is predominantly present as the mono-anion $\left(\mathrm{p} K_{\mathrm{a} 1}=2.1\right.$ and $\left.\mathrm{p} K_{\mathrm{a} 2}=7.2\right)$ and the $\mathrm{Fe}_{3} \mathrm{O}_{4}$ NPs are below their PZC and therefore will have a net positive charge. For the PAH and $\mathrm{PAH}-\mathrm{Gu}$ modified $\mathrm{Fe}_{3} \mathrm{O}_{4}$ NPs also the net surface charge is positive. The phosphate monoanion will therefore bind to the unmodified $\mathrm{Fe}_{3} \mathrm{O}_{4}$ NPs, as reported in the literature. ${ }^{19}$ Since there is hardly any extra effect of the $\mathrm{PAH}$ and $\mathrm{PAH}-\mathrm{Gu}$ modifications on the adsorbed phosphate amount it is suggested that the $\mathrm{Fe}_{3} \mathrm{O}_{4} \mathrm{NP}$ surface determines the adsorption under these conditions. Despite the positive charges at the $\mathrm{Fe}_{3} \mathrm{O}_{4} \mathrm{NP}$ surface, the stability of the PE coating under this $\mathrm{pH}$ condition can be related to the presence of neutral amino groups in the PAH and PAH-Gu chains. It is likely that both positive charges and neutral hydroxyl groups present on the $\mathrm{Fe}_{3} \mathrm{O}_{4}$ NP surface interact with the unprotonated amino groups of PEs.

Increasing the $\mathrm{pH}$ from 5 to 8 and 10 shows a reduction of phosphate adsorption by the unmodified $\mathrm{Fe}_{3} \mathrm{O}_{4}$ NPs of $46 \%$ and

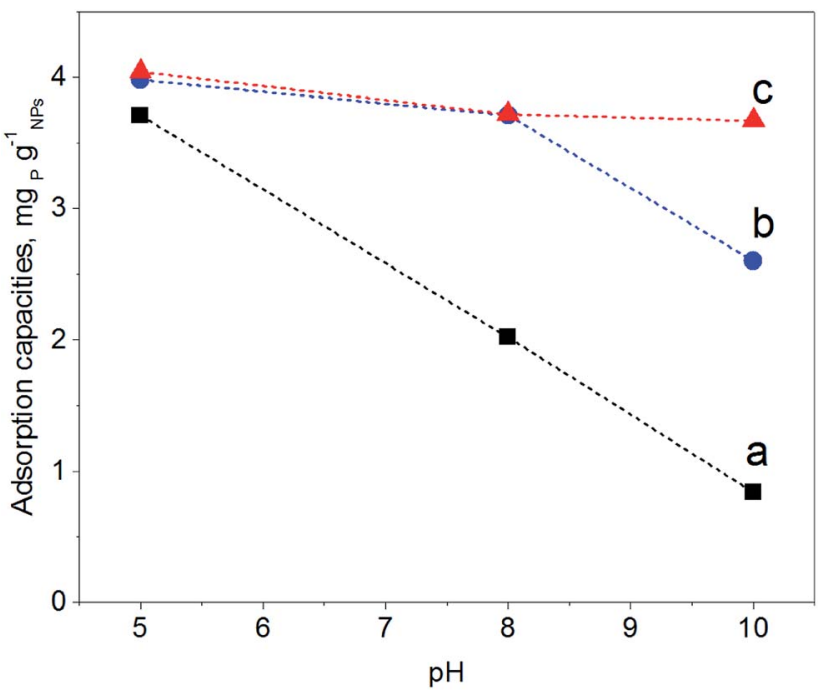

Fig. 5 Amount of phosphate adsorbed $\left(\mathrm{mg}_{\mathrm{p}} \mathrm{gNPs}^{-1}\right)$ after equilibration for $24 \mathrm{~h}$ at $\mathrm{RT}$ for (a) $\mathrm{Fe}_{3} \mathrm{O}_{4} \mathrm{NPs}$ (black), (b) $\mathrm{Fe}_{3} \mathrm{O}_{4} \mathrm{QPAH}$ (blue), and (c) $\mathrm{Fe}_{3} \mathrm{O}_{4} \mathrm{QPAH}-\mathrm{Gu}$ NPs (red). The dashed lines serve as a guide to the eye. Measurements were performed in triplicate and all errors were found to be $<0.05 \%$. 
$77 \%$, respectively. At these $\mathrm{pH}$ values, the surface charge has turned to a negative value and the adsorption of phosphate monoanions or dianions is suppressed by electrostatic repulsion. Yet, at $\mathrm{pH}=10$ the phosphate adsorption is not reduced to 0 ; instead, it is still $0.85 \mathrm{mg} \mathrm{g}^{-1}$. Thus, the adsorption of phosphate onto iron-oxide surfaces occurs both by electrostatic interactions, absent at $\mathrm{pH}=10$, and by a chemisorption process. ${ }^{\mathbf{6 6 , 6 7}}$ The latter involves the formation of $\mathrm{Fe}-\mathrm{O}-\mathrm{P}$ bonds through a ligand exchange reaction between $\mathrm{OH}$ groups at the NP surface and phosphate oxygen. This may explain the $\mathrm{P}$ adsorption detected at $\mathrm{pH}=10$.

A very clear difference is observed for $\mathrm{pH}=8$ and $\mathrm{pH}=10$, if $\mathrm{PAH}$ or $\mathrm{PAH}-\mathrm{Gu}$ is present. The amount of adsorbed phosphate is now higher than that observed for unmodified $\mathrm{Fe}_{3} \mathrm{O}_{4} \mathrm{NPs}$ and more or less similar to the adsorbed amount observed at $\mathrm{pH}=5$ for the three investigated NPs. Clearly, the reduced affinity of the (unmodified) $\mathrm{Fe}_{3} \mathrm{O}_{4}$ NP surface at $\mathrm{pH}=8$ is compensated nearly completely by the $\mathrm{PAH}$ and $\mathrm{PAH}-\mathrm{Gu}$ modifications. For $\mathrm{pH}=10$, it is seen that the phosphate adsorption for $\mathrm{PAH}$ is decreased compared to that of the $\mathrm{PAH}-\mathrm{Gu}$ modified surface. For $\mathrm{PAH}-\mathrm{Gu}$ still a phosphate adsorption of $3.67 \mathrm{mg} \mathrm{g}^{-1}$ is observed. This difference nicely reflects the difference of the $\mathrm{p} K_{\mathrm{a}}$ values of PAH (8-9) and PAH-Gu (Gu groups $\mathrm{p} K_{\mathrm{a}}=13$ ) due to which the latter has a higher positive charge density at $\mathrm{pH}=10$.

In addition, the increased stability of the colloidal suspension may contribute to the uptake of phosphate, because a higher contact area is available compared to the aggregated state. Increased colloidal stability is supported by $\zeta$-potential measurements: at $\mathrm{pH}=10$ a zeta potential of $+21.1 \mathrm{mV}$ and $+3.8 \mathrm{mV}$ is found for $\mathrm{Fe}_{3} \mathrm{O}_{4} @ \mathrm{PAH}-\mathrm{Gu}$ and $\mathrm{Fe}_{3} \mathrm{O}_{4} @ \mathrm{PAH}$, respectively. As mentioned previously, the adsorption of phosphate slightly decreases upon increasing $\mathrm{pH}$. Under alkaline conditions, $\mathrm{OH}^{-}$groups are abundant and they might compete with phosphate in the adsorption process. ${ }^{19,28}$

\section{Effect of contact time and adsorption kinetics}

Phosphate adsorption was monitored as the decrease of the phosphate concentration over time at $\mathrm{pH}$ values of 5, 8 and 10 (Fig. 6). At $\mathrm{pH}=5$ all NPs show a very fast adsorption behavior. Equilibrium was reached within $5 \mathrm{~min}$. Due to our experimental setup we are not able to accurately monitor the adsorption increase within that time frame. However, it is clear that at $\mathrm{pH}$ $=8$ and $\mathrm{pH}=10$ the adsorption process is slower, making monitoring of the adsorption increase possible. Equilibrium is now obtained within $1 \mathrm{~h}$. This is similar to observations made by others. ${ }^{29,68}$

The monitored increase of phosphate adsorption as a function of time can be nicely fitted with a pseudo-second-order kinetic equation. ${ }^{69,70}$

$$
\frac{\mathrm{d} q_{\mathrm{t}}}{\mathrm{d} t}=k_{2}\left(q_{\mathrm{e}}-q_{\mathrm{t}}\right)^{2}
$$

where $q_{\mathrm{e}}$ is the amount of phosphate adsorbed at the equilibrium, $q_{\mathrm{t}}$ is the phosphate adsorbed during the time $t$ and $k_{2}$ is the pseudo-second-order rate constant. The equation describes the increased amount of adsorbed phosphate over time as
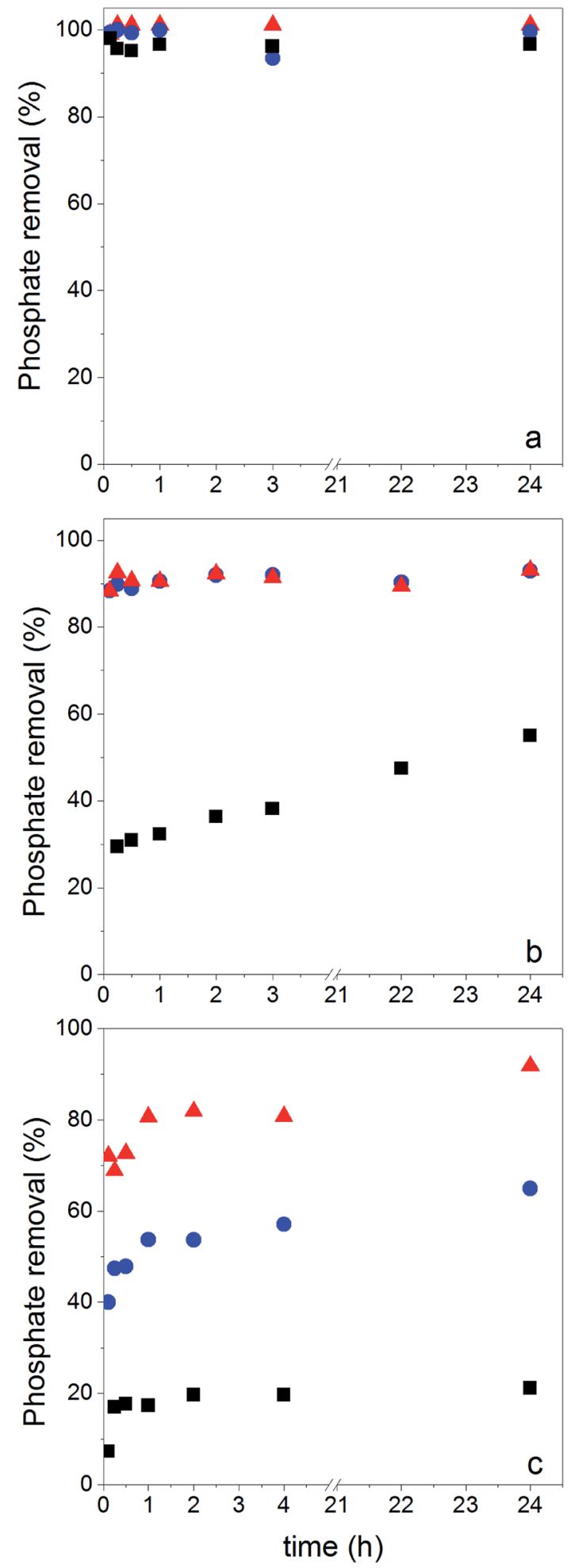

Fig. 6 Phosphate adsorption vs. time at (a) $\mathrm{pH}=5$, (b) $\mathrm{pH}=8$ and (c) $\mathrm{pH}=10$. Data were collected for bare $\mathrm{Fe}_{3} \mathrm{O}_{4}$ (black squares), $\mathrm{Fe}_{3}-$ $\mathrm{O}_{4} \mathrm{aPAH}$ (blue spheres) and $\mathrm{Fe}_{3} \mathrm{O}_{4} \mathrm{QPAH}-\mathrm{Gu}$ (red triangles). Measurements were done in triplicate and all errors were found to be lower than $0.05 \%$.

a function of the difference between $q_{\mathrm{e}}$ and $q_{\mathrm{t}}$. Although other kinetic models are reported in the literature to describe adsorption processes (i.e., pseudo-first-order, Elovich), the 
pseudo-second-order is widely recognized as the best model particularly at low initial solution concentration. ${ }^{71}$ The fit is shown for the linearized form of eqn (1), which is given by eqn (2) (fitting plots are reported in Fig. S5, $\uparrow$ while the non-linear curve fitting parameters are listed in Table $\mathrm{S} 1 \dagger$ ):

$$
\frac{t}{q_{\mathrm{t}}}=\frac{1}{k_{2} q_{\mathrm{e}}^{2}}+\frac{1}{q_{\mathrm{e}}} t
$$

In Table 3 the results of the fitting $q_{\mathrm{e}}$ and $k_{2}$ are compiled together with the calculated value of the initial rate at $t \rightarrow 0(h$ in $\mathrm{mg}^{-1} \min ^{-1}$ ),

$$
h=k_{2} q_{\mathrm{e}}^{2}
$$

and the coefficient of determination $\left(R^{2}\right)$, reflecting the quality of the fit.

As said, under conditions of $\mathrm{pH}=5$ the process is too fast for monitoring adsorption increase data and therefore we only report here experimental values of $q_{\mathrm{e}}$. Under conditions of $\mathrm{pH}=$ 8 and 10 the monitored data of increased adsorption fitted very well with the second-order kinetic equation as deduced from the obtained coefficients of determination close to unity. The observed second-order behavior is a net result of the combination of adsorption and desorption processes occurring simultaneously. ${ }^{71}$ While it is realized that the pseudo-secondorder kinetics is often ascribed to a double-site interaction, ${ }^{\mathbf{4 2 , 7 0}}$ we point to the derivation of the pseudo-second-order rate equation from the Langmuir kinetics as described by Liu and Shen. ${ }^{71}$ Double-site adsorption would be a correct physical interpretation, only if the binding sites involved can move independently over the surface and need to be close in order to bind one phosphate. However, the work of Liu and Shen ${ }^{71}$ demonstrates that the combination of the simultaneous adsorption and desorption processes also leads to apparent second-order kinetics when the total amount of binding sites per unit of volume is larger than both the initial concentration of the adsorbate and the inverse of the equilibrium binding constant. The fact that we observe second-order kinetics implies that these conditions are met.

No physical meaning can be attributed to $k_{2},{ }^{72}$ but the values for the initial adsorption rate $(h)$ and the amount of adsorbed phosphate at equilibrium $\left(q_{\mathrm{e}}\right)$ can be interpreted. At both $\mathrm{pH}=8$ and $\mathrm{pH}=10, h$ increases from $\mathrm{Fe}_{3} \mathrm{O}_{4}$ NPs to
$\mathrm{Fe}_{3} \mathrm{O}_{4} @ \mathrm{PAH}$ to $\mathrm{Fe}_{3} \mathrm{O}_{4} @ \mathrm{PAH}-\mathrm{Gu}$. At $\mathrm{pH}=10, q_{\mathrm{e}}$ also increases in this order. In contrast, at $\mathrm{pH}=8$ for $\mathrm{Fe}_{3} \mathrm{O}_{4}$ @PAH and $\mathrm{Fe}_{3} \mathrm{O}_{4} @ \mathrm{PAH}-\mathrm{Gu}$ a similar order of $q_{\mathrm{e}}$ is observed, which is higher than that of $\mathrm{Fe}_{3} \mathrm{O}_{4}$ NPs. It is suggested therefore that at $\mathrm{pH}=8$ the adsorption capacity of the two investigated polyelectrolytes is similar. The difference between the two polyelectrolytes becomes visible at $\mathrm{pH}=10$, in favor of $\mathrm{Fe}_{3} \mathrm{O}_{4} @ \mathrm{PAH}-\mathrm{Gu}$, showing a $\mathrm{pH}$-independent value of $q_{\mathrm{e}}$. This is likely due to the differences in the $\mathrm{p} K_{\mathrm{a}}$ of the $\mathrm{PAH}$ and $\mathrm{PAH}-$ $\mathrm{Gu}$ PEs; the Gu moieties are still protonated at $\mathrm{pH}=10$, while for $\mathrm{PAH}$ the degree of protonation is reduced compared to the situation at $\mathrm{pH}=8$. From the results shown in Table 3 , it is also clearly seen that at $\mathrm{pH}=8$ and $\mathrm{pH}=10$ the phosphate adsorption is dictated by the present PEs and that the dominant role observed for $\mathrm{Fe}_{3} \mathrm{O}_{4}$ at $\mathrm{pH}=5$ is now tempered. An additional difference between $\mathrm{Fe}_{3} \mathrm{O}_{4} @ \mathrm{PAH}$ and $\mathrm{Fe}_{3} \mathrm{O}_{4} @$ @$\mathrm{PAH}-\mathrm{Gu}$ (not shown here) is the selectivity for phosphate binding for the Gu containing polyelectrolytes, which we have shown in our previous study. ${ }^{38}$

\section{Reversibility of phosphate binding}

The reversibility of the adsorption process is highly relevant when it comes to practical applications. Initially we run desorption experiments under high alkaline conditions ${ }^{43}(\mathrm{pH}=$ 12.9) to weaken the electrostatic interaction between $\mathrm{PAH}-\mathrm{Gu}$ and phosphate. While a high phosphate desorption was obtained this way $(>80 \%)$, the NPs were found to agglomerate and it was difficult to get them re-dispersed. Hence, the second adsorption cycle was unsuccessful and the NPs were not reusable, likely caused by a partial removal of the $\mathrm{PAH}-\mathrm{Gu}$ coating, which acts as a coagulant for $\mathrm{Fe}_{3} \mathrm{O}_{4}$ NPs. ${ }^{54}$ However, phosphate could be removed successfully from $\mathrm{Fe}_{3} \mathrm{O}_{4} @ \mathrm{PAH}-\mathrm{Gu}$ NPs by a regeneration process using $10 \mathrm{mM}$ of $\mathrm{NaCl}$ solution through an anion-exchange mechanism. Phosphate adsorption and desorption were monitored over three cycles (Fig. 7) and high levels of phosphate recovery were reached in good agreement with previous work reported in the literature. ${ }^{26,42}$ After the first cycle, the adsorption of phosphate was decreased in the next cycle by almost $20 \%$, which might be explained by phosphate being irreversibly bound to (and/or physically entrapped in) the NPs and PAH-Gu network or to a decrease of the available active surface caused by a partial NP aggregation after the centrifugation steps.

Table 3 Kinetic model parameters obtained from pseudo-second-order model fitting to experimental time-dependent adsorption data for phosphate on $\mathrm{Fe}_{3} \mathrm{O}_{4}, \mathrm{Fe}_{3} \mathrm{O}_{4} \mathrm{QPAH}$, and $\mathrm{Fe}_{3} \mathrm{O}_{4} \mathrm{QPAH}-\mathrm{Gu}$ at $\mathrm{pH}=5,8$ and 10 . For completeness, the $q_{\mathrm{e}}$ values experimentally determined at $24 \mathrm{~h}$ $\left(q_{\mathrm{e}}\right.$ exp) are included

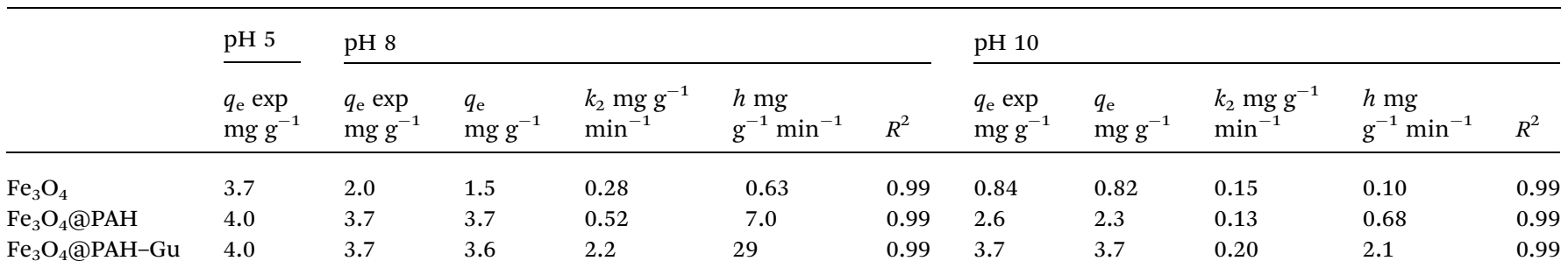




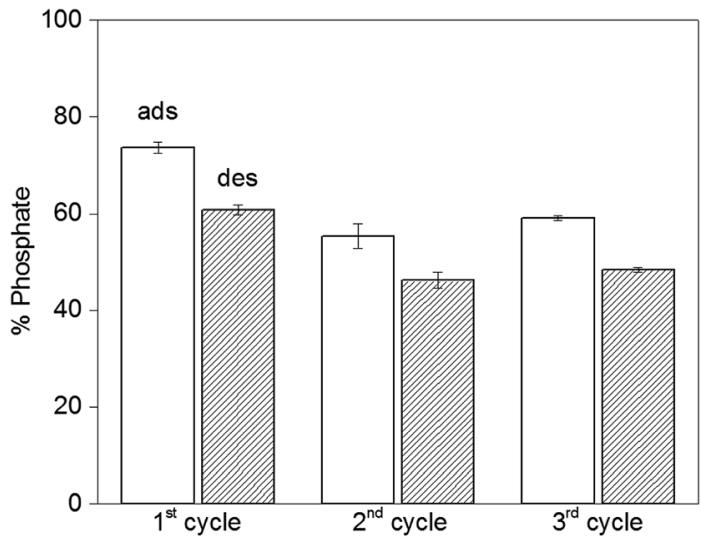

Fig. 7 Recovery of phosphate for $\mathrm{Fe}_{3} \mathrm{O}_{4} \mathrm{QPAH}-\mathrm{Gu}$ over three cycles; empty columns give the adsorption data after $24 \mathrm{~h}$, while the filled columns show the desorption results. NPs were regenerated with a $10 \mathrm{mM} \mathrm{NaCl}$ solution at $\mathrm{RT}$ and $\mathrm{pH}=5$, the adsorbent dosage was $0.5 \mathrm{~g} \mathrm{~L}^{-1}$ and the initial phosphate concentration was $5 \mathrm{mg} \mathrm{L}^{-1}$.

\section{Conclusions}

While several nanomaterials have been investigated for the removal of phosphate from aqueous (wastewater) streams, it remains a challenge to develop new systems operable under alkaline conditions. This study shows the results of a simple surface modification method applied to commercially available $\mathrm{Fe}_{3} \mathrm{O}_{4}$ NPs by using a polyelectrolyte functionalized with guanidinium groups for phosphate anion binding. The surface modification was confirmed by thermal, morphological and surface analysis measurements (FTIR, XPS and $\zeta$-potential analysis). The $\mathrm{PAH}-\mathrm{Gu}$ modified $\mathrm{Fe}_{3} \mathrm{O}_{4}$ NPs showed good phosphate adsorption $\left(3.7 \mathrm{mg} \mathrm{g}^{-1}\right)$ up to $\mathrm{pH}=10$, where the phosphate adsorption ability of the PAH-modified $\mathrm{Fe}_{3} \mathrm{O}_{4}$ $\left(2.3 \mathrm{mg} \mathrm{g}^{-1}\right)$ and unmodified $\mathrm{Fe}_{3} \mathrm{O}_{4}\left(0.82 \mathrm{mg} \mathrm{g}^{-1}\right)$ is reduced. The initial rate of phosphate adsorption increased from 2.1 to $29 \mathrm{mg} \mathrm{g}^{-1} \mathrm{~min}^{-1}$ for PAH-Gu coated $\mathrm{Fe}_{3} \mathrm{O}_{4}$ NPs upon switching the $\mathrm{pH}$ from 10 to 8 . The observed second-order adsorption kinetics can be explained as the net result of simultaneous adsorption and desorption processes at the NP surface. At the same time, the colloidal stability was enhanced upon coating the NPs with polyelectrolytes. Finally, the reversibility of phosphate binding to the novel $\mathrm{Fe}_{3} \mathrm{O}_{4} @ \mathrm{PAH}-\mathrm{Gu}$ NPs was studied over three cycles of adsorption and desorption, showing the reusability of the NPs. While already most $(>80 \%)$ of the bound phosphate could be released again, we believe that the efficiency can be further improved by additional advanced surface modification strategies, e.g. by covalently binding the coating to the NPs and capping the remaining surface hydroxyl groups.

\section{Acknowledgements}

The authors thank Wetsus - European centre of excellence for sustainable water technology (Leeuwarden, the Netherlands) for financial support and Dr Henk Miedema (Wetsus) and Mr Willem van Baak (FUJIFILM Manufacturing Europe BV, The Netherlands) for their support and fruitful discussions. This study was partly supported by the European Research Council (ERC Consolidator Grant 682444, E-motion, PI De Smet). The authors thank Dr Wiel Evers and Mr Yi Song (both TU Delft) for obtaining the TEM images and experimental support, respectively.

\section{References}

1 J. Schröder, D. Cordell, A. L. Smit and A. Rosemarin, Sustainable use of phosphorus, 2010.

2 FAO, Current world fertilizer trends and outlook to 2016, 2012.

3 J. J. Hudson, W. D. Taylor and D. W. Schindler, Nature, 2000, 400, 55-56.

4 G. E. Conley, D. J. H. Paerl, W. Howarth, R. W. Boesch, D. F. Seitzinger, S. P. Havens, K. E. Lancelot and C. Likens, Science, 2009, 323, 1014-1015.

5 E. Levlin, M. Löwén, B. Stark and K. Hultman, Water Sci. Technol., 2002, 46, 435-440.

6 European Commission, Common implementation strategy for the water framework directive (200/60/EC), 2009.

7 E. Desmidt, K. Ghyselbrecht, Y. Zhang, L. Pinoy, B. Van der Bruggen, W. Verstraete, K. Rabaey and B. Meesschaert, Crit. Rev. Environ. Sci. Technol., 2015, 45, 336-384.

8 D. P. Van Vuuren, A. F. Bouwman and A. H. W. Beusen, Global Environ. Change., 2010, 20, 428-439.

9 T. Mino, M. C. M. Van Loosdrecht and J. J. Heijnen, Water Res., 1998, 32, 3193-3207.

10 Y. Zhang, B. Van der Bruggen, L. Pinoy and B. Meesschaert, J. Membr. Sci., 2009, 332, 104-112.

11 S. U. Hong, L. Ouyang and M. L. Bruening, J. Membr. Sci., 2009, 327, 2-5.

12 B. Tran, A. T. K. Tran, A. T. K. Zhang, Y. De Corte, D. Hannes, J. B. Ye, W. Mondal and P. Van Der Bruggen, J. Cleaner Prod., 2014, 77, 140-151.

13 X. Hao, C. Wang, M. C. M. Van Loosdrecht and Y. $\mathrm{Hu}$, Environ. Sci. Technol., 2013, 47, 4965-4966.

14 K. Karageorgiou, M. Paschalis and G. N. Anastassakis, J. Hazard. Mater., 2007, 139, 447-452.

15 S. Sen Gupta and K. G. Bhattacharyya, Adv. Colloid Interface Sci., 2011, 162, 39-58.

16 P. Wilfert, P. Suresh Kumar, L. Korving, G.-J. Witkamp and M. C. M. Van Loosdrecht, Environ. Sci. Technol., 2015, 49, 9400-9414.

17 C. T. Yavuz, J. T. Mayo, W. W. Yu, A. Prakash, J. C. Falkner, S. Yean, L. Cong, H. J. Shipley, A. Kan, M. Tomson, D. Natelson and V. L. Colvin, Science, 2006, 314, 964-967.

18 K. Mandel, A. Drenkova-Tuhtan, F. Hutter, C. Gellermann, H. Steinmetz and G. Sextl, J. Mater. Chem. A, 2013, 1, 18401848.

19 Y. Li, Q. Xie, Q. Hu, C. Li, Z. Huang, X. Yang and H. Guo, Sci. Rep., 2016, 6, 1-11.

20 H. Qu, D. Caruntu, H. Liu and C. J. O'Connor, Langmuir, 2011, 27, 2271-2278.

21 Y. P. Sun, X. Q. Li, W. X. Zhang and H. P. Wang, Colloids Surf., A, 2007, 308, 60-66.

22 V. Sarapulova, E. Nevakshenova, N. Pismenskaya, L. Dammak and V. Nikonenko, J. Membr. Sci., 2015, 479, 28-38. 
23 H. Huang, J. Yang and D. Li, Bioresour. Technol., 2014, 172, 253-259.

24 D. Guaya, M. Hermassi, C. Valderrama, A. Farran and J. L. Cortina, J. Environ. Chem. Eng., 2016, 4, 3519-3526.

25 H. Wang, X. Xu, R. Fei and B. Gao, RSC Adv., 2016, 6, 4723747248.

26 A. Abo Markeb, A. Alonso, A. D. Dorado, A. Sánchez and X. Font, Environ. Technol., 2016, 3330, 1-14.

27 J. Zhang, J. Han, M. Wang and R. Guo, J. Mater. Chem. A, 2017, 5, 4058-4066.

28 L. Guo Yan, K. Yang, R. Shan, T. Yan, J. Wei, S. Jun Yu, H. Qin Yu and B. Du, J. Colloid Interface Sci., 2015, 448, 508-516.

29 D. N. H. Tran, S. Kabiri, L. Wang and D. Losic, J. Mater. Chem. A, 2015, 3, 6844-6852.

30 J. J. Richardson, M. Bjornmalm and F. Caruso, Science, 2015, 348, 1-11.

31 R. Femmer, A. Mani and M. Wessling, Sci. Rep., 2015, 5, 112.

32 F. Caruso, Adv. Mater., 2001, 13, 11-22.

33 Y.-W. Choi, H. Lee, Y. Song and D. Sohn, J. Colloid Interface Sci., 2015, 443, 8-12.

34 S. Wijeratne, M. L. Bruening and G. L. Baker, Langmuir, 2013, 29, 12720-12729.

35 S. Wijeratne, W. Liu, J. Dong, W. Ning, N. D. Ratnayake, K. D. Walker and M. L. Bruening, ACS Appl. Mater. Interfaces, 2016, 8, 10164-10173.

36 D. Ullien, P. J. Harmsma, S. M. C. Abdulla, B. M. de Boer, D. Bosma, E. J. R. Sudhölter, L. C. P. M. de Smet and W. F. Jager, Opt. Express, 2014, 22, 16585-16594.

37 L. van der Mee, E. S. Y. Chow, L. C. P. M. de Smet, M. de Puit, E. J. R. Sudhölter and W. F. Jager, Anal. Methods, 2015, 7, 10121-10124.

38 Z. Cao, P. I. Gordiichuk, K. Loos, E. J. R. Sudhölter and L. C. P. M. de Smet, Soft Matter, 2016, 12, 1496-1505.

39 K. Schug and W. Lindner, Chem. Rev., 2005, 105, 67-114.

40 Z. Xiong, Y. Chen, L. Zhang, J. Ren, Q. Zhang, M. Ye, W. Zhang and H. Zou, ACS Appl. Mater. Interfaces, 2014, 6, 22743-22750.

41 F. Caruso, Chem.-Eur. J., 2000, 6, 413-419.

42 S. Y. Yoon, C. G. Lee, J. A. Park, J. H. Kim, S. B. Kim, S. H. Lee and J. W. Choi, Chem. Eng. J., 2014, 236, 341-347.

43 O. Eljamal, A. M. E. Khalil, Y. Sugihara and N. Matsunaga, Chem. Eng. J., 2016, 293, 225-231.

44 Laboratory Research in Environmental Engineering, Phosphorus Determination using the Colorimetric Ascorbic Acid Technique, 2001.

45 Water Environment Federation, Standard Methods for the Examination of Water and Wastewater, 1999.

46 I. Szilagyi, G. Trefalt, A. Tiraferri, P. Maroni and M. Borkovec, Soft Matter, 2014, 10, 2479-2502.

47 G. Lamanna, M. Kueny-Stotz, H. Mamlouk-Chaouachi, C. Ghobril, B. Basly, A. Bertin, I. Miladi, C. Billotey,
G. Pourroy, S. Begin-Colin and D. Felder-Flesch, Biomaterials, 2011, 32, 8562-8573.

48 J. Choi and M. F. Rubner, Macromolecules, 2005, 38, 116-124. 49 B. Jachimska, T. Jasiski, P. Warszyski and Z. Adamczyk, Colloids Surf., A, 2010, 355, 7-15.

50 A. Pantos, I. Tsogas and C. M. Paleos, Biochim. Biophys. Acta, Biomembr., 2008, 1778, 811-823.

51 S. E. Burke and C. J. Barrett, Langmuir, 2003, 19, 3297-3303.

52 P. Maroni, F. J. Montes Ruiz-Cabello, C. Cardoso and A. Tiraferri, Langmuir, 2015, 31, 6045-6054.

53 J. E. Wong, A. K. Gaharwar, D. Müller-Schulte, D. Bahadur and W. Richtering, J. Nanosci. Nanotechnol., 2008, 8, 40334040.

54 T. Wang, L. Zhang, H. Wang, W. Yang, Y. Fu, W. Zhou, W. Yu, K. Xiang, Z. Su, S. Dai and L. Chai, ACS Appl. Mater. Interfaces, 2013, 5, 12449-12459.

55 F. Tristán, G. Palestino, J.-L. Menchaca, E. Pérez, H. Atmani, F. Cuisinier and G. Ladam, Biomacromolecules, 2009, 10, 2275-2283.

56 X. Lin, L. Wu, Y. Liu, A. L. Ong, S. D. Poynton, J. R. Varcoe and T. Xu, J. Power Sources, 2012, 217, 373-380.

57 A. Szpak, G. Kania, T. Skorka, W. Tokarz, S. Zapotoczny and M. Nowakowska, J. Nanopart. Res., 2013, 15, 1372.

58 J. S. Stevens, A. C. De Luca, M. Pelendritis, G. Terenghi, S. Downes and S. L. M. Schroeder, Surf. Interface Anal., 2013, 45, 1238-1246.

59 L. Li and S. Zheng, Ind. Eng. Chem. Res., 2015, 54, 171-180.

60 Y. Lai, W. Yin, J. Liu, R. Xi and J. Zhan, Nanoscale Res. Lett., 2009, 5, 302-307.

61 L. Zhang, N. Zhou, B. Wang, C. Liu and G. Zhu, J. Colloid Interface Sci., 2014, 421, 1-5.

62 P. Liu, X. Li, B. Mu, P. Du, X. Zhao and Z. Zhong, Ind. Eng. Chem. Res., 2012, 51, 13875-13881.

63 D. L. Wilcox and M. Berg, MRS Proceedings, 1994, 372, 3.

64 R. Davies, G. A. Schurr, P. Meenan, R. D. Nelson, H. E. Bergna, C. A. S. Brevett and R. H. Goldbaum, Adv. Mater., 1998, 10, 1264-1270.

65 S. D. Sajjad, Y. Hong and F. Liu, Polym. Adv. Technol., 2014, 25, 108-116.

66 R. Chitrakar, S. Tezuka, A. Sonoda, K. Sakane, K. Ooi and T. Hirotsu, J. Colloid Interface Sci., 2006, 298, 602-608.

67 J. Kim, W. Li, B. L. Philips and C. P. Grey, Energy Environ. Sci., 2011, 4, 4298-4305.

68 Z. Zhu, H. Zeng, Y. Zhu, F. Yang, H. Zhu, H. Qin and W. Wei, Sep. Purif. Technol., 2013, 117, 124-130.

69 D. Robati, J. Nanostruct. Chem., 2013, 3, 1-6.

70 Y. Ho, J. Hazard. Mater., 2006, 136, 681-689.

71 Y. Liu and L. Shen, Langmuir, 2008, 24, 11625-11630.

72 Y. Miyake, H. Ishida, S. Tanaka and S. D. Kolev, Chem. Eng. J., 2013, 218, 350-357. 